\title{
El Proyecto de Gobernanza Global: La teoría general de Derechos Humanos frente a la soberanía estatal
}

\section{The Global Governance Project: The general theory of Human Rights versus state sovereignty}

Norma Yolanda Villacís Venegas. ${ }^{1}$

\begin{abstract}
DOI: $\underline{\text { https://doi.org/10.33262/visionariodigital.v4i3.1270 }}$
This research analyzes the tension between the Universal Declaration of Human Rights and its general theory, approved in 1945, against state sovereignty, from its approaches: popular and national. The hypothesis raised is that a cosmopolitan vision of the theory of human rights limits the decision-making of democratic citizens of the different nations of the world, advocating in its place, for a pluralist vision of power, that promotes a new theory of human rights, that it be multiculturalist and avoid the unequivocal imposition of western values, as a hegemonic form of universal culture. For this work, we will use as a methodology of scientific research, the pluralistic vision of power and the method of bibliographic review in the framework of analysis of political theory and philosophy of law, which reflects on the normative principles that underlie the qualification of law and politics. In the theoretical framework we present the main concepts that guide this work, for the formation of thought in the state of the art that enables the definition of conclusions.
\end{abstract}

Keywords: Human rights, state sovereignty, global governance, globalization, State.

\section{Resumen.}

Esta investigación analiza la tensión existente, entre la Declaración Universal de Derechos Humanos y su teoría general, aprobada en 1945, frente a la soberanía estatal, desde sus enfoques: popular y nacional. La hipótesis planteada es que, una

\footnotetext{
${ }^{1}$ Escuela Superior Politécnica de Chimborazo, Sede Morona Santiago, Ambato, Ecuador. norma.villacis@espoch.edu.ec
} 
visión cosmopolita de la teoría de los derechos humanos limita la toma de decisiones de los ciudadanos democráticos de las diferentes naciones del mundo, abogando en su reemplazo, por una visión pluralista del poder, que promueva una nueva teoría de los derechos humanos, que sea multiculturalista y evite la imposición inequívoca de los valores occidentales, como forma hegemónica de la cultura universal. Para este trabajo, usaremos como metodología de la investigación científica, la visión pluralista del poder y el método de revisión bibliográfica en el marco de análisis de la teoría política y la filosofía del derecho, que reflexiona sobre los principios normativos que subyacen bajo el calificativo de derecho y política. En el marco teórico presentaremos los principales conceptos que guían este trabajo, para la formación del pensamiento en el estado del arte que posibilitan la definición de conclusiones.

Palabras clave: Derechos humanos, soberanía estatal, gobernanza global, globalización, Estado.

\section{Introducción.}

Esta investigación no busca poner en cuestión el trabajo de los tribunales penales internacionales, como la Corte Penal Internacional, que juzgan delitos de lesa humanidad, a través de la suscripción de tratados internacionales sobre derecho humanitario internacional; esta investigación, lo que pone a consideración es la misma concepción de la teoría general de los derechos humanos, fundamentada en la Declaración Universal de los Derechos Humanos, suscrita en 1948 como máxima expresión de la dignidad humana. Por lo que, la pregunta de investigación se centra en comprender las tensiones permanentes que existirían entre el concepto de derechos humanos y la soberanía estatal. Partiendo de una tensión previa entre derecho internacional y nacional.

La hipótesis planteada es que, siendo un esfuerzo noble el realizado en la elaboración de los treinta artículos que comprenden la Declaración Universal de los Derechos Humanos, hoy, esa visión se pone en cuestión, pues sería una visión occidental de los valores que comprenden la dignidad humana; lo que pondría en duda la concepción de 'universalidad' de la cual se encuentra investida la teoría general de derechos humanos, para ser desnudada más bien como la construcción hegemónica de una cultura "universal", lo anula la pluralidad del multiculturalismo.

Con este trabajo, más que abogar por un mundo de aislamiento y nacionalismo exacerbado, lo que presentamos es un problema en cuestión, de empezar a pensar un mundo multicultural que incluya los valores diversos que nos cruzan como civilización humana, precisamente como antídoto y vacuna frente a los ultra nacionalistas, que van encontrar en aquellos cosmopolitas que abogan por la universalización, el caldo de cultivo para crear sentimientos de xenofobia global, si desde ya, reconocemos como un problema real y presente, el contar con visiones únicas de nuestra realidad, que además son 
construcciones desde occidentes, las clases marginales en los bordes de la política, rápidamente van a ser tentadas por los discursos extremistas que con construcciones de la política populistas, dividen a la sociedad entre los traidores de la patria y los verdaderos nacionales. Políticos como Donald Trump en EEUU, Viktor Orban en Hungría o Marine Le Pen en Francia son producto de este mundo cosmopolita, que ha perdido de vista las construcciones culturales que se viven desde los márgenes de la política, por eso desde la teoría del derecho crítico, se puede repensar estas formas de construcción del derecho universal, entendido como derecho internacional público y derecho humanitario y producir nuevas teorías y figuras normativas que permitan hacer tratados y convenios e internacionales más abiertos hacia el mundo, acogiendo lo mejor, de todas nuestras formas de cultura alrededor del globo.

\section{Metodología.}

En este trabajo de investigación, voy a usar como base y método de investigación, la visión pluralista del poder, de Nelson W. Polsby y la teoría de los Stakeholders de Mikkel Flyverborn. La visión pluralista del poder es la premisa desde la cual partimos, pues para este trabajo, entendemos al poder desde la geopolítica, como un orden mundial dominado por relaciones de poder multipolares, por eso que use el método de investigación pluralista pues, ayuda a entender que hay más que un solo poder hegemónico, aun siendo este poder cosmopolita, lo que ha dispersado y generado nuevos focos de poder. Y como fuente de apoyo doctrinario o base teórica, voy a usar el trabajo de Mikkel Flyverbom, en su libro 'el poder en las redes', sobre los stakeholders como grupos sociales que ejercen presión en los grupos de trabajo en organismos internacionales.

También en este trabajo se usará, como marco teórico referencial los trabajos de Boaventura de Sousa Santos, quien tiene varios estudios, investigaciones y trabajos publicados sobre su crítica de la teoría de los derechos humanos, desde la sociología, como su campo de pensamiento principal. Es así como, en este trabajo se trae esta visión desde la sociología crítica al campo de pensamiento de la ciencia política y, más claramente al de la teoría política, al ponerle en cuestión frente a la soberanía estatal y los estudios enfocados en teoría del Estado.

Como señalan Chuliá y Agulló (2012: 28): “investigación en teoría política [es] aquella cuyo principal objetivo consiste en reflexionar y discutir sobre los principios normativos que subyacen a cualquier actividad que merezca el calificativo de "política'", por lo que el principal método a usarse es el de la revisión bibliográfica, del cual parten los análisis y confluyen en las conclusiones.

\section{Estado y soberanía.}

Las revoluciones liberales de finales del siglo XVIII y comienzos del siglo XIX terminan con el sistema feudal y su instrumentalización política manifestada en la monarquía y 
crean una nueva forma de organización política: el Estado, que se presentaba como "la realidad de la idea moral" y "la imagen y la realidad de la razón" (Hegel), que además con las ideas de los ideólogos de la revolución francesa, se conceptualiza como el pacto social entre los ciudadanos para su autogobierno, así entonces el Estado nace para ponerle un freno a los poderes de la monarquía y posteriormente con hechos como la Revolución de Octubre, a ser usado para detener los poderes del mercado y abolir la burguesía, y en los modelos del Estado de Bienestar ponerle un límite a los mismos, todo esto teniendo como pilar fundamental la soberanía popular y nacional, en relación con los aportes de Jean Jacques Rousseau de la autodeterminación de los pueblos y el mandato popular como única fuente de legitimación del ejercicio del poder por parte del Estado.

La tensión entre Estado y derechos humanos nace con base en la razón entre los cambios de continuidad entre regímenes políticos y derechos humanos. Una disputa en varios campos de batalla, que se rige entre derecho internacional y nacional. En las violaciones de los derechos humanos y las declaratorios de Estado de excepción. La formación de las comisiones de la verdad, de los esfuerzos de memoria histórica, de las declaraciones y cancelaciones de amnistía, son reflejo claro de esas disputas presentes entre ambos campos de acción. Entre los derechos humanos y la acción de los regímenes políticos (Santos, 2014: 49)

Uno de los grandes embates que sufre el Estado y su soberanía frente a los derechos humanos, está por la normatividad creada de violación de derechos humanos, únicamente ligada al ejercicio del poder estatal. Es evidente que las violaciones de derechos humanos se presentan en otras tantas esferas. Las milicias privadas y las empresas transnacionales y sus poderes económicos.

Son unos pocos de muchos ejemplos que existen sobre violaciones de derechos humanos, que pierden su foco de atención, al centrar toda la defensa de los derechos humanos únicamente al frente al Estado. Esta aceptación no es casualidad, sino causalidad. Y es que viene ligada al inicio de la historia de los derechos humanos, que generalmente nos ha sido presentada como estadios generacionales. La primera generación de derechos humanos son los civiles y políticos que nacen precisamente al poder del Estado absolutista. Pero, la segunda generación, que son los derechos sociales y políticos son, por el contrario, el uso y ocupación del Estado para la prohibición y garantía de estos derechos frente a otros poderes exógenos, especialmente el económico (Santos, 2014: 44)

Es necesario marcar las pautas diferenciadoras entre el rechazo o anti-estatismo de comienzos del siglo XIX, en la teoría liberal de entonces, que eran voluntades democráticas frente al absolutismo estatal y el discurso actual neoliberal que aupa sus fuerzas fundamental en el desmantelamiento del Estado del bienestar y el pacto social, lo que lo hace reaccionario y antidemocrático, socavando los principios del ejercicio de la soberanía en favor del libre comercio y la globalización (Santos, 2014: 46) 


\section{La desterritorialización del Estado}

El problema de la desterritorialización del Estado afecta seriamente al mismo en la medida en que este pierde el control sobre las dinámicas que se efectúan dentro del mismo, es decir, dentro de su espacio de control y, por lo tanto, se ve mermada su soberanía.

La globalización, (entendida como parte de un conjunto de medidas económicas, políticas y culturales) como se ha dicho antes, es uno de los factores para entender esta crisis. Este término tan abstracto como es la globalización no se puede caracterizar como una "fuerza suprahumana que actuaría con independencia de las prácticas de los actores sociales", (Mato, 2000:149) sino que hay que entender que este impulso de las actividades globales, más exactamente, de los flujos globales, han de ser impulsadas por algún tipo de actor amparado en una teoría que delinee el modo de operar. Este hecho, impulsó la internacionalización de flujos que ya se daban mayoritariamente. Pero este carácter que se le da a la globalización mayoritariamente, desde un aspecto económico que ha determinado el resto de las áreas de la vida, deviene de una hegemonización de la concepción misma de la globalización que, si bien no hay que reducir la globalización al neoliberalismo, hay que tener presente que el tipo de globalización que ha erosionado la capacidad del Estado ha sido capitaneado por el neoliberalismo mismo (Mato, 2000). Se entiende, por tanto, que "la crisis del Estado está asociada, por un lado, al carácter cíclico de la intervención estatal y, por otro, al proceso de globalización, que reduce la autonomía de las políticas económicas y sociales de los estados nacionales” (Bresser, 1998:521).

Por lo que, cabría defender una comprensión de la globalización y la erosión que ha producido en el Estado desde una perspectiva que resalta que esa actividad no sucede de la nada, sino que es una política concreta y deliberada por unos actores determinados. Este hecho es claramente visible a partir del momento en el que la tasa de ganancia es decreciente para el capitalista (año 1965 aprox.) debido a la caída de la tasa de ganancia, no es hasta principios de los años ochenta cuando se da una oleada neoliberal en la que la tasa de beneficio vuelve a crecer nuevamente (aunque no en la misma medida que en la época dorada del Estado de Bienestar) (Brooks, 2013).

Se dice, por tanto, que la globalización ha producido la erosión del Estado al desterritorializar procesos que han llevado a la crisis de este. Pero esta desterritorialización no ha venido de la nada, sino que ha sido impulsada por unas prácticas determinadas de unos actores concretos para mitigar un problema central (tasa de beneficio decreciente). El tránsito del capitalismo fordista insertado en el Estado de Bienestar al neofinanciero transnacional ha requerido tanto de políticas desreguladoras a nivel internacional (FMI, G-20...) como a nivel nacional (socialización del pago de la deuda, prioridad en su pago...), apoyando además este paso entre fordismo y capitalismo financiero en el menoscabo de la soberanía estatal, lo que nos daría claves para entender la facilidad con la que el discurso de los derechos humanos han sido usados para la 
disminución del monopolio legítimo de la violencia, que otrora que llegara a poseer el Estado, usando las concepciones sobre Estado de Max Weber.

Desde la implementación de la acepción normativa de los derechos humanos. En correlación con la desterriorización del Estado en pro de los organismos supraestatales. Está presente un discurso de ambivalencia, entre prácticas y principios. Mientras parece que desde 1948 se evocan, proclaman y defienden los derechos humanos. Se los viola sistemáticamente, en varios casos con la complicidad de los organismos internacionales que dicen precautelarlos. Así, en nombre de la seguridad y la lucha contra el terrorismo, se violan derechos civiles, de privacidad y libertad. Se invaden naciones so pretexto de estas violaciones de los derechos humanos, por Estados no alineados con los intereses hegemónicos. Bloqueos económicos que afectan a los derechos sociales y perpetuo detrimento de la calidad de vida de las personas, por el ensanchamiento de las brechas de la desigualdad (Aguiló, 2009:185-188).

\section{Representación y soberanía popular}

El Estado moderno, está asociado a la idea de la representación, por lo menos en las sociedades occidentales, de ahí que, de forma normativa se liga la idea de la democracia representativa con la de soberanía popular, pues el representante ejerce su poder soberano con base en el mandato popular otorgado a él en las urnas; el problema surge pues: "la crisis del Estado está asociada, por un lado, al carácter cíclico de la intervención estatal $\mathrm{y}$, por otro, al proceso de globalización, que reduce la autonomía de las políticas económicas y sociales de los estados nacionales" (Bresser, 1998:521), que es un efecto de la globalización como proceso cultural y económico, en el que, además las funciones producto de las revoluciones liberales vigentes en las democracias occidentales, han sido aplicadas en todas las potencias del norte y sus satélites y antiguos territorios de conquista, especialmente África y América Latina (Cotta, 2007:266), es por esto que, en todas estos países, desde la adopción del legislativo, como una función más dentro de las tres funciones clásicos, un rasgo primordial sea el de la representación y este órgano colegiado de legislación, donde mejor se materializa, la idea misma del representante y representado $y$, es por esta relación que, los ciudadanos generan un nexos causal entre las instituciones de la democracia representativa y los políticos que acceden a ellas, esto quiere decir que, los problemas de políticos en forma particular se los correlaciona como problemas de la instituciones en sí mismas, generando desafección política por parte del soberano hacia los mandantes, que en este caso son los legisladores, en este ejercicio de lógica causal, es cuando la representación y representatividad se ven entrelazadas y el elector pierde de vista la línea diferenciadora entre ambos conceptos. De esta manera, cuando el ciudadano elige a su representante, el soberano manifiesta su intención como máxima expresión democrática y las leyes se ven investidas de legitimidad, por haber sido promulgadas por órganos asamblearias de legisladores elegidos por voto directo; esta legitimidad está ausente en la promulgación de los Tratados y Convenios Internacionales y está ausente en la Declaración Universal de Derechos Humanos. 
Así, para que una política pública o una ley resulte representativa, es necesario que responda a las demandas del electorado, pues en ese momento se verá investida de legitimidad (Cotta, 2007:268), demandas que desconocen los cuerpos diplomáticos y las burocracias tecnócratas de los organismos supraestatales, legislando con base en sus propias interpretaciones del bien general, sin respaldo en una representación conferida por el voto.

Los defensores del cosmopolitismo han caído en intentar dar un ropaje democrático, a los organismos internacionales, que no poseen. Las decisiones democráticas, siempre tienen beneficios colectivos pero que afectan a grupos específicos. La democracia provee de mecanismos de impugnación ante estas decisiones. Por eso es tan importante la delimitación de un demo capaz de decidir quienes deberían impugnar en su nombre. Por esto, no es necesario intentar cubrir de legitimidad a las estructuras supraestatales llamándolas democráticas. Lo más cercano, es entenderlas como sistemas burocráticos en los que hay que admitir que existen costes a la democracia, pero que sus decisiones pueden traer beneficios que suplen esos costes nacionales. (Dahl, 1999:25)

Toda visión cosmopolita -en sus diferentes vertientes- niega la condición de conflicto y negatividad inherente de lo político, por lo que niega la exteriorización de la hegemonía. Una visión de una democracia global cosmopolita, con ciudadanos cosmopolitas que comparte, entienden y ejercen sus derechos, es una visión peligrosa del futuro. Ese mundo sería uno en el que el poder hegemónico -negado previamente como hegemónicoencontraría como ilegitimo cualquier cuestionamiento a su poder y su liderazgo racional, haciendo una analogía de sus intereses con los de la humanidad en si misma (Mouffe, 2011:114)

\section{La Globalización y la visión pluralista del poder.}

La globalización es la internacionalización e interdependencia de las economías nacionales en un plano mundial, que confluyen en un mercado común global que busca eliminar las barreras arancelarias para la "liberación" de la economía, los efectos de la globalización han superado los esquemas económicos entrando en aspectos sociales propios de las naciones, parte de este proceso empieza con eliminar las identidades culturales locales, por esquemas mundiales de vestimenta, música, tradiciones y costumbres que se convierten en un producto más de un mundo globalizado, que promoviendo el enriquecimiento económico desconoce las raíces históricas de los pueblos. La globalización viene a poder en entredicho, al estado-nación y por ende al concepto de soberanía y representación, pues nos presenta una sola forma de entender y ejercer la ciudadanía en términos liberales, nos moraliza la política global y nos obliga asumir valores como inequívocos y universales, lo que limita el derecho a la libre determinación de los pueblos, lo que significa que las naciones ya no pueden gobernarse a sí mismas, ni encontrar sus propias formas de organización (Mouffe, 2011:108), pues no solo se imponen desde organismos supraestatales en marcos comunes, como la Unión 
Europea, sino que también se los imponen desde organismos internacionales como las Naciones Unidas, frente a los cuales se nos dice que no existe otro órgano de apelación y al cual todas las naciones están supeditadas, a pesar de que en gran parte de los casos responden a los intereses de las naciones centrales, dejando desplazados a los estados periféricos. Esos organismos de imposición internacional, además, en general elaboran tratados y convenios internacionales que, aunque el derecho internacional exige que deben ser aprobados y ratificados por cada país, muchas veces los invocan en nombre de la democracia y la libertad. Estas normas internacionales, son además construidas cada vez con más frecuencia sobre los valores occidentales, sin que en su núcleo se conciba a las diferentes normas de convivencia de las diferentes culturales del mundo, son visiones unidimensionales de la realidad global, que anula la multiculturalidad (Mouffel, 2011:109), que busca obviar los contextos culturales de las diversas regiones del planeta.

Esta visión cosmopolita niega la visión pluralista del poder, en la que se rechaza la idea de que siempre un mismo grupo, domina el ejercicio del poder en la comunidad (Polsby, 1960, p.65), que, para efectos de esta investigación, interpreto el concepto de 'comunidad', como aquellas usadas en relaciones internacionales, o sea, la comunidad internacional.

La teoría general de los Derechos Humanos como poder constitutivo de legitimidad. Según Prieto G, (2012): "En la dialéctica construida en el contexto internacional a partir de la Declaración Universal de los Derechos Humanos de 1948, el respeto a los derechos humanos va a suponer un límite al poder político del Estado soberan2o" (p.15). Por lo que, de forma generalizada en la academia, se acepta que la teoría general de Derechos Humanos, tal y como es entendida actualmente, si es un limitante al poder político de la soberanía estatal, por lo que ese punto está comprobado. Pero, los tribunales de justicia internacional y el Consejo de Seguridad de Naciones Unidas, han autorizado inclusive intervenciones militares, invocando los derechos humanos, como en el caso de la legalidad en la invasión a Irak en 2001 (Taylor, 2018). Lo que pone, en relieve que el poder constitutivo, que, en derecho constitucional, es la teoría que justifica cual es el origen del ejercicio del poder (Bockenforde, 2000), derivaría para efectos de esta investigación, directamente de la Declaración Universal de los Derechos Humanos, como acto originario de poder.

Pero, aunque esa visión, podría suponer que existe una legitimidad formal, en la Declaración Universal de los Derechos Humanos, no encontraríamos esa justificación aplicable a la legitimidad material, que se fundamenta en la premisa de que, el ejercicio del poder en las decisiones de los poderes estatales está legitimado en el hecho de que, quienes elaboran las leyes a nivel nacional, fueron votados en elecciones libres (Cajica, 2002). Pero, en el trabajo que realizan los técnicos de los organismos internacionales, no se observa que respetan ningún parámetro de voluntad popular, al no haber sido elegidos en las urnas y porque, como observa Flyverbom: "particular social worlds were cast and mobilized as stakeholders" (2011, p.52), por lo que quienes terminan influenciando en el 
trabajo de los burócratas de los organismos supraestatales, terminan siendo los stakeholders, que están movilizados por los grupos de presión internacionales, lo que quiere decir, las grandes transnacionales.

Por el contrario, la concepción de los derechos humanos, reposa sobre supuestos diferentes, que son: el entender a la naturaleza humana como superior a la realidad, el individualismo como valor protegido frente a la sociedad y el Estado, que deben ser la suma de individuos libres, evitando la jerarquización, que vaya en detrimento de esa forma de individualización y que estos elementos componen una dignidad absoluta y univoca del ser humano, que se entiende conocida por todos como formas de racionalidad compartidas por el humano (Panikkar, 1984:30). Todos estos valores en los que se fundamenta el concepto de derechos humanos resultarán evidentes para el lector, que son valores occidentales, específicamente liberales que, al sopesarse con otras formas de pensamiento en las diferentes latitudes del mundo, es evidente que muestran diametrales diferencias con los valores y el concepto de dignidad para otras culturas.

Esto desemboca en el problema de la comprensión actual de los derechos humanos que, en términos de construcción cultural, es un proceso de globalización desde arriba, pues mientras ostenten la calidad de universales, serán usados como instrumento del choque de civilizaciones, en términos de Samuel Huntington, en tanto que una lucha entre occidente contra los demás. (Santos, 2002: 66)

Una visión plural del ejercicio del poder. Puede llevarnos a una concepción mestiza de los derechos humanos. Una aproximación que repose sus construcciones de normatividad compartidas, en las redes de legitimidad local. En donde la renuncia a los falsos universalismos, nos permitan un dialogo intercultural, sobre la base de la concepción de la dignidad humana (Santos, 2002:70)

Para el ejercicio de esta visión plural. Es necesario reposar en los aspectos culturales, que construyen los conceptos normativos. Así siempre existen dos formas de aproximación cultural, una más amplia y otra más cerrada. En el mundo musulmán, se presentan. Y el mundo occidental es claro, que hay dos mundos de aproximación la liberal y la socialdemócrata o marxista. De estas, la primera tiende a tener la visión cerrada, por lo que son más útiles los supuestos de los cuales parten las concepciones occidentales culturales socialdemócratas y marxistas, que incorporan a la igualdad a las esferas económicas y sociales y no solo la arrinconan al espacio de la esfera pública, como hace la aproximación liberal (Santos, 2002: 79)

\section{Conclusiones:}

- Entendiendo a la Declaración Universal de los Derechos Humanos, como poder constitutivo originario que deviene de un acto que es, la voluntad de las naciones de unirse después de la segunda guerra mundial para crear un documento que 
ponga básicos sobre los principios que conforman la dignidad humana, esta normativa internacional tiene legitimidad internacional y se invoca en varios momentos de la historia política de las sociedades occidentales; pero ese es precisamente el punto de inflexión que se pone en cuestión, pues es una teoría general de derechos humanos pensada desde occidente, desde los valores que se defienden en esas sociedades, dejando de lado las visiones multiculturales de lo que comprende la dignidad humana, para las sociedades asiáticas, latinoamericanas y de los pueblos originarios del mundo.

- El sistema de globalización neoliberal ha extendido su injerencia de acción al campo cultural, legitimando procesos de imposición por parte de organismos internacionales, en detrimento de la soberanía nacional y popular, lo que provoca el rechazo de varios sectores, de ambos extremos cartesianos del espectro ideológico, poniendo en cuestión el tipo de globalización que vivimos y si es la que mejor entiende el multiculturalismo mundial.

- Mediante esta forma de actuar el Estado fue perdiendo peso y soberanía dentro de sus fronteras ya que se dio una desterritorialización de las fronteras a favor de las empresas transnacionales y organismos supranacionales. Por este motivo, los ciudadanos de los propios estados veían cómo las decisiones muchas veces se tomaban fuera de su territorio y deslegitimaban una vez más a sus propios representantes. En quienes en última instancia ven reflejada la soberanía estatal.

- Debemos caminar hacia un orden multipolar, más ligado al contexto actual de los grandes centros económicos mundiales, en donde configuremos una nueva teoría general de los derechos humanos, una teoría multicultural de los derechos humanos, que acoja los valores del multiculturalismo mundial y los incorpore en la cada vez más occidentalizada idea, de lo que significa la dignidad humana, leyes internacionales redactadas sin que se impongan por tratados internacionales cada vez más sesgados a una visión única del mundo, a los cuales ni siquiera de las potencias del norte, que los promueven se comprometen a suscribirlos, pero se imponen como verdades únicas al resto de naciones.

\section{Referencias bibliográficas:}

Aguiló, A. (2009). Los Derechos Humanos como campo de luchas por la diversidad humana: Un análisis desde la sociología crítica de Boaventura de Sousa Santos. Universitas humanística no.68 julio-diciembre de 2009 pp: 179-205. Bogotá colombia issn 0120-4807.

Bockenforde, E-W. (2000). Estudios sobre el estado de derecho y la democracia. Madrid: Ed. Trotta. 
Bresser, C. (1998). La reforma del Estado de los años noventa: lógica y mecanismos de control. Revista de ciencias sociales de Buenos Aires. Desarrollo económico, 38(150), 517-550.

Brooks, M. (2013). Capitalist Crisis-Theory and Practice. Londres: Expedia.

Cajica, G. (2002). Estado Constitucional de Derecho y Legitimidad Democrática. México: Biblioteca jurídica virtual del instituto de investigaciones jurídicas de la UNAM.

Cotta, M. (2007). Representación democrática en Europa. Ed: Oxford University Press.

Chulia, E., y Agullo, M. (2012). Cómo se hace un Trabajo de Investigación en Ciencia Política. Madrid: La Catarata

Dahl, R. (1999). Can international organizations be democratic? A skeptic's view. In I. Shapiro \& C. Hacker-Cordón (Eds.), Democracy's Edges (Contemporary Political Theory, pp. 19-36). Cambridge: Cambridge University Press. doi:10.1017/CBO9780511586361.003

Fenichel Pitkin, H. (1985). El concepto de representación. Madrid. Centro de estudios constitucionales.

Flyverbom, M. (2011). The Power of Networks: Engaging Social Worlds as Stakeholders. Pp. 38-65. Edward Elgar Publishing Ltd.

Gutiérrez, D. (2014). Boaventura de Sousa Santos y la reconstrucción intercultural de los derechos humanos. Año 0, No. 5, julio 2014. Buenos Aires: Analéctica.

Mato, D. (2000). Des-fetichizar la "globalización": basta de reduccionismos, apologías y demonizaciones; mostrar la complejidad y las prácticas de los actores. RELEARevista Latinoamericana de Estudios Avanzados, 13, 147-177.

Mouffel, C. (2011). En torno a lo político. Buenos Aires: Fondo de Cultura Económica.

Polsby, Nelson W. (1960). How to study community power: the pluralist alternative. Journal of Politics, vol.22, pp. 478-484. Londres y Nueva York: Ed. Routledge.

Prieto Godoy, C. A. (2012). Ejercicio del derecho de asilo en la normativa comunitaria y nacional (Doctoral dissertation, Universidad Complutense de Madrid). 
Pannikar, R. (1984). Is the Notion of Human Rights a Western Concept?, en Cahier, $81: 28-47$.

Santos, B. (2014). Derechos humanos, democracia y desarrollo. Bogotá: Centro de Estudios de Derecho, Justicia y Sociedad.

Santos, B. (2002). Hacia una concepción multicultural de los derechos humanos. EL OTRO DERECHO, número 28. Julio de 2002. ILSA, Bogotá D.C., Colombia.

Taylor, Rachel S. World Press Review associate editor. (2018). Recuperado el 7 de enero de 2020 de: https://www.worldpress.org/specials/iraq/. 
PARA CITAR EL ARTÍCULO INDEXADO.

Villacís Venegas, N. Y. (2020). El Proyecto de Gobernanza Global: La teoría general de Derechos Humanos frente a la soberanía estatal. Visionario Digital, 4(3), 19-31. https://doi.org/10.33262/visionariodigital.v4i3.1270

\section{¿Ciencia}

El artículo que se publica es de exclusiva responsabilidad de los autores y no necesariamente reflejan el pensamiento de la Revista Visionario Digital.

El artículo queda en propiedad de la revista y, por tanto, su publicación parcial y/o total en otro medio tiene que ser autorizado por el director de la Revista Visionario Digital.
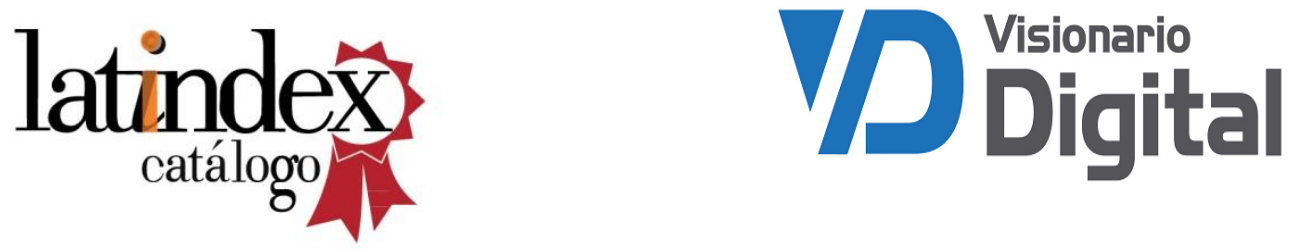